\title{
СИНТЕЗ НОВОГО АМИДНОГО ПРОИЗВОДНОГО ВАЛЬПРОЕВОЙ КИСЛОТЫ И 1,3,4-ТИАДИАЗОЛА С ПРОТИВОЭПИЛЕПТИЧЕСКОЙ АКТИВНОСТЬЮ
}

\section{А. С. Малыгин'®, М. А. Демидова', С. Я. Скачилова², Е. В. Шилова²}

1 Тверской государственный медицинский университет, Тверь, Россия

${ }^{2}$ Всесоюзный научный центр по безопасности биологически активных веществ, Старая Купавна, Московская область, Россия

\begin{abstract}
Вальпроаты являются основными препаратами для лечения эпилепсии различных форм. Среди проблем, возникающих при их клиническом использовании, - фармакорезистентность, нежелательные побочные реакции, а также проявления острой и хронической интоксикации. Путем модификации химической структуры вальпроевой кислоты возможно создание более эффективных и безопасных антиконвульсантов. Перспективно получение тиадиазолиламидных производных вальпроатов, так как 1,3,4-тиадиазол может повышать биодоступность и снижать токсичность лекарственных средств. Целью работы был синтез нового амидного производного вальпроевой кислоты и 1,3,4-тиадиазола с противоэпилептической активностью. Химическую структуру синтезированного вальпроата исследовали методами ИК-спектроскопии, 1Н-ЯМР, 13С-яМР-спектроскопии, масс-спектроскопии и элементного анализа. Чистоту и индивидуальность подтверждали методами тонкослойной и высокоэффективной жидкостной хроматографий. Противоэпилептическую активность оценивали в тесте антагонизма с изониазидом (250 мг/кг, интраперитонеально) у мышей методом пробит-анализа. В результате исследования был получен N-(5-этил-1,3,4-тиадиазол-2-ил)-2-пропилпентанамид (вальпразоламид). ESI+-масс-спектр N-(5-этил-1,3,4-тиадиазол-2-ил)-2-пропилпентанамида - m/z 256,1 [M + H]+ , МRM-переходы — m/z 256,1 - m/z 81,0 и m/z 130,1. Синтезированный вальпроат оказывал противоэпилептическое действие при изониазид-индуцированных судорогах у мышей. Значение ЕD тесте антагонизма с изониазидом составило 126,8 мг/кг (95\% ДИ: 65,5-245,4). Терапевтический индекс был равен 7,3.
\end{abstract}

Ключевые слова: противоэпилептические средства, вальпроевая кислота, 1,3,4-тиадиазол

Вклад авторов: А. С. Малыгин - экспериментальное исследование, анализ результатов, обзор публикаций по теме статьи, написание текста; М. А. Демидова - концепция и дизайн исследования, написание и редактирование текста; С. Я. Скачилова, Е. В. Шилова - синтез и анализ соединения; все авторы участвовали в обсуждении результатов.

Соблюдение этических стандартов: исследование одобрено этическим комитетом Тверского государственного медицинского университета (протокол № 4 от 26 марта 2018 г.). Подопытных животных содержали согласно правилам лабораторной практики при проведении доклинических исследований в РФ (Приказ МЗ РФ № 199н от 01.04.2016 «Правила надлежащей лабораторной практики»). Все эксперименты осуществляли в соответствии с методическими рекомендациями по проведению доклинических исследований лекарственных средств с соблюдением «Европейской конвенции о защите позвоночных животных, используемых для экспериментов или в иных научных целях» (Directive 2010/63/EU).

$\bowtie$ Для корреспонденции: Александр Сергеевич Малыгин ул. Советская, д. 4, г. Тверь, 170100; dr.a.s.m@yandex.ru

Статья получена: 17.01.2020 Статья принята к печати: 03.02.2020 Опубликована онлайн: 09.02.2020

DOI: $10.24075 /$ vrgmu.2020.007

\section{SYNTHESIS OF A NOVEL AMIDE DERIVATIVE OF VALPROIC ACID AND 1,3,4-THIADIAZOLE WITH ANTIEPILEPTIC ACTIVITY}

Malygin $\mathrm{AS}^{1 \otimes}$, Demidova MA¹, Skachilova SYa², Shilova EV²

1 Tver State Medical University, Tver, Russia

${ }^{2}$ All-Russian Research Center for the Safety of Bioactive Substances, Staraya Kupavna, Moscow region, Russia

Valproates are commonly used to treat various forms of epilepsy. Problems accompanying their clinical application include drug resistance, adverse effects, acute and chronic toxicity. Safer anticonvulsants with improved efficacy can be obtained through the chemical modification of valproic acid structure. Thiadiazole-linked amide derivatives of valproates hold great promise because 1,3,4-thiadiazole can improve the drug's bioavailability and reduce its toxicity. The aim of this work was to synthesize a novel amide derivative of valproic acid and 1,3,4-thiadiazole exerting antiepileptic activity. The chemical structure of the synthesized valproate was studied by IR, proton NMR and 13C-NMR-spectroscopy, mass spectroscopy and elemental analysis. The purity and individuality of the compound was confirmed by thin-layer and high-performance liquid chromatography. Its antiepileptic activity was assessed in the test with intraperitoneally injected 250 mg/kg isoniazid and subsequent Probit analysis. The synthesized N-(5-ethyl-1,3,4-thiadiazol-2-yl)-2-propyl pentane amide (valprazolamide) had the following characteristics. ESI+MS: $\mathrm{m} / \mathrm{z} 256.1[\mathrm{M}+\mathrm{H}]^{+}$; MRM transitions: $\mathrm{m} / \mathrm{z} 256.1-\mathrm{m} / \mathrm{z} 81.0$ and $\mathrm{m} / \mathrm{z} 130.1$. The valproate exerted antiepileptic activity against isoniazid-induced seizures in mice. In the test with isoniazid, $\mathrm{ED}_{50}$ of intraperitoneally injected VPZ was $126.8 \mathrm{mg} / \mathrm{kg}$ (95\% Cl: 65.5-245.4). Its therapeutic index was 7.3 .

Keywords: antiepileptic drugs, valproic acid, 1,3,4-thiadiazole

Author contribution: Malygin AS — laboratory tests; data analysis; literature analysis; manuscript preparation; Demidova MA — study concept and design; manuscript preparation; Skachilova SYa, Shilova EV - synthesis and analysis of the compound; All authors equally contributed to the discussion of the study results.

Compliance with ethical standards: the study was approved by the Ethics Committee of Tver State Medical University (Protocol № 4 dated March 26, 2018). The animals were treated in compliance with the guidelines for laboratory practice in preclinical trials (Order 199n of the Russian Ministry of Healthcare dated April 1, 2016 , on the Good laboratory practice). All tests were carried out in accordance with the guidelines for preclinical trials of medicinal drugs and in compliance with the European Convention for the Protection of Vertebrate Animals Used for Experimental and other Scientific Purposes (Directive 2010/63/EU).

$\triangle$ Correspondence should be addressed: Alexandr S. Malygin

Sovetskaya, 4, Tver, 170100; dr.a.s.m@yandex.ru

Received: 17.01.2020 Accepted: 03.02.2020 Published online: 09.02.2020

DOI: 10.24075/brsmu.2020.007 
Эпилепсией страдает более 75 млн людей по всему миру, и их число постоянно растет [1-2]. Ключевая проблема современной эпилептологии - фармакорезистентность, низкий процент больных эпилепсией (14,9\%), достигающих стойкой ремиссии. У 48,1\% происходят повторные приступы с частотой до 12 раз в год [3-4]. Половина больных эпилепсией получают несколько антиконвульсантов одновременно. Часть пациентов страдают от нерациональной замены препаратов, необоснованной политерапии, ухудшающей качество жизни, повышающей вероятность возникновения нежелательных лекарственных реакций. Остро стоит проблема приверженности лечению: 18,05\% больных эпилепсией в России не получают лекарственной терапии [5]. Оптимизация фармакотерапии эпилепсии - важнейшая задача эпилептологии.

Среди многочисленных антиконвульсантов особое положение занимает вальпроевая кислота, которую синтезировал в 1882 г. Беверли С. Бертон и первоначально использовали в качестве растворителя. Противосудорожные свойства вальпроевой (2-пропилпентановой) кислоть случайно открыли в 1963 г. и с тех пор широко используют в клинической практике [6]. Вальпроаты являются противоэпилептическими средствами широкого спектра действия, в связи с чем их относят к препаратам первого выбора при эпилепсии различных форм. Долгосрочные исследования показали эффективность вальпроатов при всех формах генерализованных эпилепсий [7-9]. Существенная проблема в использовании вальпроатов нежелательные побочные реакции, а также проявления острой и хронической интоксикации [10-12]. Изза высокой тератогенности они не рекомендованы женщинам детородного возраста [13]. За счет химической модификации вальпроевой кислоты возможно получение более эффективных и безопасных препаратов с антиконвульсивной активностью [14].

Целью исследования было получить новый антиконвульсант из группы тиадиазолиламидных дериватов вальпроевой кислоты.

\section{МАТЕРИАЛЫ И МЕТОДЫ}

\section{Реагенты и препараты}

2-Амино-5-этил-1,3,4-тиадиазол (Acros Organics; Бельгия), 2-пропилпентановая кислота (Sigma Aldrich; США), пиридин («ЛенРеактив»; Россия), изониазид («Мосхимсрармпрепараты им. Н. А. Семашко»; Россия), хлористоводородная кислота («ЛенРеактив»; Россия), пропанол-2 («ЛенРеактив»; Россия), ацетонитрил (LC-MS; Scharlau, Испания), ацетат аммония (Panreac AppliChem ITW reagents, США), этанол («Медхимпром»; Россия), вода деионизированная Milli-Q.

\section{Оборудование}

Масс-селективный квадрупольный детектор AB Sciex QTrap 3200 MD (Sciex; Сингапур), высокоэффективный жидкостный хроматограф Agilent 1260 Infinity II (Agilent Technologies; Германия), пластины для тонкослойной хроматографии (силикагель 60 F 254) (Merck; Германия), спектрометр Bruker Avance-400 (Bruker; Германия), ИКспектрометр Agilent Cary 630 FIIR (Agilent; Германия), анализатор для элементного анализа EA 1108 (Carlo Erba Instruments; Италия), аналитические весы Acculab ALC80d4 (Acculab; CШA), центрифуга с охлаждением ротора Eppendorf 5810R (Eppendorf; Германия), система получения особо чистой воды Миллипор DirectQ UV (Millipore SAS; Франция), вортекс-встряхиватель Elmi V-3 (Elmi; Латвия), шейкер Elmi S-3 (Elmi; Латвия), термостат твердотельный «Термит» («ДНК-Технология»; Россия), автоматические дозаторы Eppendorf (Eppendorf; Германия) и Black Thermo («Термо Фишер Сайентифик»; Россия).

\section{Методы идентификации}

Химическую структуру синтезированного вальпроата (N-(5-этил-1,3,4-тиадиазол-2-ил)-2-пропилпентанамида) исследовали методами ИК-спектроскопии, 1Н-ЯМР, 13С-яМР-спектроскопии, масс-спектроскопии и элементного анализа. Чистоту и индивидуальность подтверждали методами тонкослойной и высокоэффективной жидкостной хроматографии.

\section{Экспериментальная оценка противоэпилептической активности}

Противоэпилептическую активность синтезированного вальпроата оценивали в тесте антагонизма с изониазидом. Генерализованные клонико-тонические судороги индуцировали у мышей интраперитонеальным введением изониазида $($ ИЗН) в дозе 250 мг/Кг [15]. Использовали аутбредных мышей-самцов SNK массой 19-21г $(n=40)$. Животных содержали в условиях вивария Тверского ГМУ при постоянной температуре $\left(22 \pm 2^{\circ} \mathrm{C}\right)$ и искусственном 12-часовом режиме дня и ночи (светлое время 08:0020:00) со свободным доступом к воде и пище. Мыши были рандомизированы на пять групп: контрольную (изониазид-индуцированные судороги) и опытные группы (интраперитонеальное введение тестируемого препарата в дозах 75, 150, 300 и 450 мг/кг за 40 мин до изониазида). Видеонаблюдение за подопытными животными осуществляли в течение 3 ч, регистрируя латентный период первого судорожного приступа, появление клонических и тонических судорог, исходы (выживание или гибель). Рассчитывали значения $\mathrm{ED}_{50}$ (средней терапевтической дозы, обеспечивающей выживание 50\% животных в тесте) и терапевтического индекса $\left(\mathrm{TI}=\mathrm{DL}_{50} / \mathrm{ED}_{50}\right.$ - отношение среднесмертельной дозы к средней терапевтической).

\section{Статистические методы исследования}

Статистический анализ проводили с использованием программы «BioStat, 2009» (AnalystSoft; США). Для обработки результатов исследования применяли методы описательной статистики. После проверки гипотезы o нормальном распределении данных с помощью W-критерия Шапиро-Уилка проводили однофакторный дисперсионный анализ (ANOVA) c апостериорным сравнением (post-hoc тест множественного сравнения) с помощью критерия Тьюки HSD. Для статистического анализа относительных показателей использовали точный критерий Фишера. Данные представляли в виде $m \pm$ SEM. Значение $\mathrm{ED}_{50}$ рассчитывали путем пробит-анализа методом Финни.

\section{РЕЗУЛЬТАТЫЫ ИССЛЕДОВАНИЯ}

\section{Схема синтеза}

Синтезированный тиадиазолиламидный дериват вальпроевой кислоты - N-(5-этил-1,3,4-тиадиазол-2-ил)-2-пропилпентанамид 
(брутто формула $\mathrm{C}_{12} \mathrm{H}_{21} \mathrm{~N}_{2} \mathrm{OS}$ ) с лабораторным наименованием вальпразоламид (ВПЗ) представлен на рис. 1.

Синтез нового антиконвульсанта состоял из следующих этапов: галогенирование 2-пропилпентановой кислоть хлорангидридом сернистой кислоты; стехиометрическое взаимодействие полученного хлорангидрида 2-пропилпентановой кислоты с 2-амино-5-этил-1,3,4тиадиазолом; получение кристаллического осадка при подкислении реакционной массы $\mathrm{HCl}$ до $\mathrm{pH}=1-2$ при температуре $5^{\circ} \mathrm{C}$ (рис. 2).

После синтеза осуществляли очистку полученного продукта. Поэтапная очистка включала: удаление водорастворимых примесей путем промывания охлажденной водой с повторной фильтрацией и перекристаллизацию с пропанолом-2 после предварительного высушивания в вакууме при 10 мм рт. ст. до постоянной массы (выход 67\%). Эфффективность очистки контролировали хроматограсфическими методами (ТСХ и ВЭЖХХ).

\section{Описание и идентификация}

\section{N-(5-этил-1,3,4-тиадиазол-2-ил)-2-пропилпентанамида}

Полученная активная фрармацевтическая субстанция белый с желтоватым оттенком кристаллический порошок молярная масса 255,14 г/моль, температура плавления 93-94 ${ }^{\circ} \mathrm{C}$. Практически не растворим в воде, растворим в спирте, в ацетонитриле и других органических растворителях

Химическую структуру N-(5-этил-1,3,4-тиадиазол-2ил)-2-пропилпентанамида $\left(\mathrm{C}_{12} \mathrm{H}_{21} \mathrm{~N}_{3} \mathrm{OS}\right)$ подтверждали методом элементного анализа и с помощью спектральных характеристик. Расчетным путем для $\mathrm{C}_{12} \mathrm{H}_{21} \mathrm{~N}_{3} \mathrm{OS}$ было определено содержание элементов: C — 56,44\%; H 8,29\%; N - 16,45\%; O - 6,26\%; S - 12,56\%. Элементный анализ показал содержание C - 56,39\%; H - 8,34\%; N $16,41 \%$; O - 6,26\%; S - 12,60\%, что соответствовало химической структуре синтезированного соединения.

Результаты спектроскопии: ИК-спектры (при таблетировании с KBr), v/cm ${ }^{-1}$ : 3302, 3030 (NH), 2981, 2959, 2860 (CH), 1545 (NHCO); ${ }^{1} \mathrm{H}-9 M P(400$ МГц, DMSO-d $)$ $\delta$ ppm: 0,97 (s, 3H, $\left.\mathrm{CH}_{3}\right), 1,33\left(\mathrm{~s}, 2 \mathrm{H}, \mathrm{CH}_{2}\right), 1,41-1,50(\mathrm{~m}$, $4 \mathrm{H}), 2,65$ (s, 2H, $\left.\mathrm{CH}_{2}\right), 10,63$ (s, $\left.1 \mathrm{H}, \mathrm{NH}\right) ;{ }^{13} \mathrm{C}-9 M P(400 \mathrm{MГц,}$ DMSO-d) $\delta$ ppm: 13,48, 13,66, 20,06, 24,70, 35,27, 43,22 155,85, 156,5, 175,00; ESI+-масс-спектр - m/z 256,1 ([M + H]+), значения MRM-переходов - m/z 256,1 $\rightarrow$ m/z 81,1 и m/z 130,1. ESI+-масс-спектр N-(5-этил-1,3,4-тиадиазол-2-ил)2-пропилпентанамида представлен на рис. 3.

Индивидуальность синтезированного антиконвульсанта оценивали с помощью ВЭЖХ. Хроматограсию проводили с использованием колонки Phenomenex synergi Fusion 4 мкм-С18 2 × 50 мм, при температуре $50^{\circ} \mathrm{C}$. Элюирование осуществляли метанолом с водой деионизированной в соотношении 90: 10 и с добавлением 0,1\%-го аммония ацетата. Время удерживания составило 1,31 мин (рис. 4).

\section{Оценка противоэпилептической активности на модели изониазид-индуцированных судорог у мышей}

При интраперитонеальном введении изониазида (250 мг/Кг) генерализованные клонико-тонические судороги со смертельным исходом развивались у всех подопытных мышей группы контроля. Предварительное введение ВПЗ за 40 мин до изониазида оказывало дозозависимое влияние на течение изониазид-индуцированных судорог у мышей $(p<0,0001$; односакторный дисперсионный анализ ANOVA). ВПЗ в дозе 75 мг/кг статистически значимо увеличивал продолжительность латентного периода первого судорожного приступа в среднем в 1,5 раза $(p<0,05)$ по сравнению с контролем, однако не предупреждал развития судорог и гибели подопытных животных. При использовании ВПЗ в дозах 150 мг/кг и 300 мг/кг наряду с увеличением латентного периода первого судорожного приступа отмечено уменьшение числа смертельных исходов. В серии опытов с использованием ВПЗ в дозе 450 мг/кг развития судорожного синдрома в течение 3 ч после введения изониазида зарегистрировано не было (см. табл.).

По результатам пробит-анализа значение $\mathrm{ED}_{50}$ при интраперитонеальном введении ВПЗ в тесте антагонизма с изониазидом составило 126,8 мг/Кг (95\% ДИ: 65,5-245,4). Терапевтический индекс был равен 7,3.

\section{ОБСУЖДЕНИЕ РЕЗУЛЬТАТОВ}

Основные критерии для поиска новых антиконвульсантов эффективность при фармакорезистентной эпилепсии, меньшее количество побочных эффектов, лучшая переносимость, а также способность замедлять прогрессирование и модифицировать течение

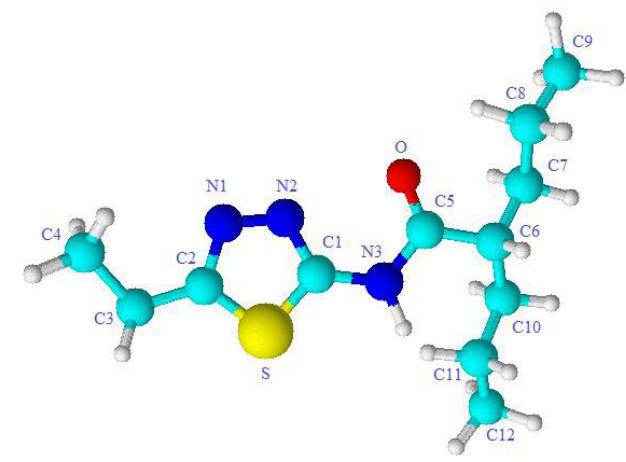

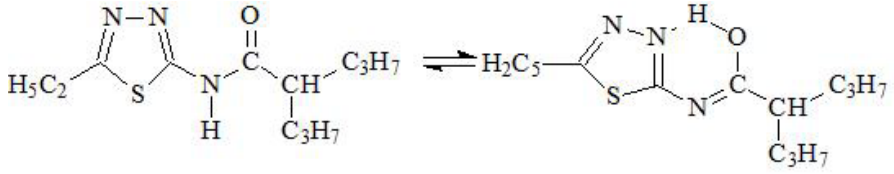

Рис. 1. N-(5-Этил-1,3,4-тиадиазол-2-ил)-2-пропилпентанамид

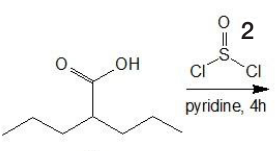

1

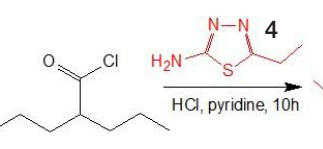

3

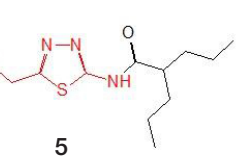

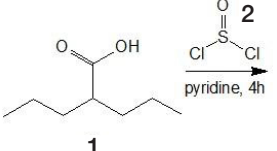

1

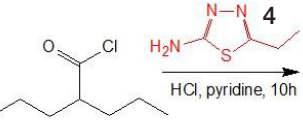

3

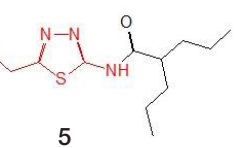

Рис. 2. Схема синтеза N-(5-этил-1,3,4-тиадиазол-2-ил)-2-пропилпентанамида. 1 - 2-пропилпентановая кислота; 2 - хлорангидрид сернистой кислоты; 3 - хлорангидрид 2-пропилпентановой кислоты; 4 - 2-амино-5-этил-1,3,4-тиадиазол; 5 - N-(5-этил-1,3,4-тиадиазол-2-ил)-2-пропилпентанамид 
эпилепсии; дополнительные преимущества линейность фармакокинетики, легкость титрации при клиническом использовании, наличие дополнительных терапевтических эффеектов, в том числе обезболивающего при невропатической боли. Поиск таких препаратов осуществляют как среди новых молекул, так и путем создания новых производных известных антиконвульсантов.

В литературе показана возможность создания новой генерации вальпроатов [16]. Отмечено, что тератогенность амидных аналогов существенно ниже, чем у самой вальпроевой кислоты [17]. Среди амидов вальпроевой кислоты выявлены эффективные противоэпилептические [18], антиневропатические [19-20], противовирусные [21-22] и другие средства. Антиконвульсивная активность обнаружена также у ряда производных 1,3,4-тиадиазола, в том числе содержащих остаток вальпроевой кислоты [23]. Большинство тиадиазоловых производных отличалось от аналогов более высокой биодоступностью и меньшей токсичностью. Подобная закономерность отмечена и в отношении синтезированного вальпроата, содержащего в своей структуре 1,3,4-тиадиазолил. Показано, что значение полулетальной дозы 1,3,4-тиазиазолиламидного

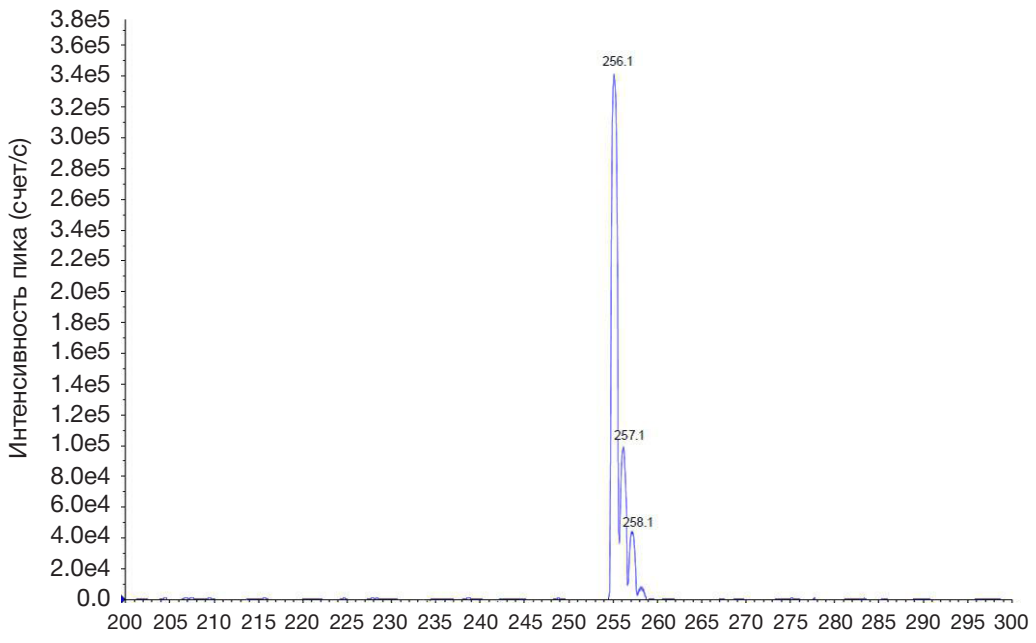

Рис. 3. ESI+-масс-спектр N-(5-этил-1,3,4-тиадиазол-2-ил)-2-пропилпентанамида ([M + H]+)

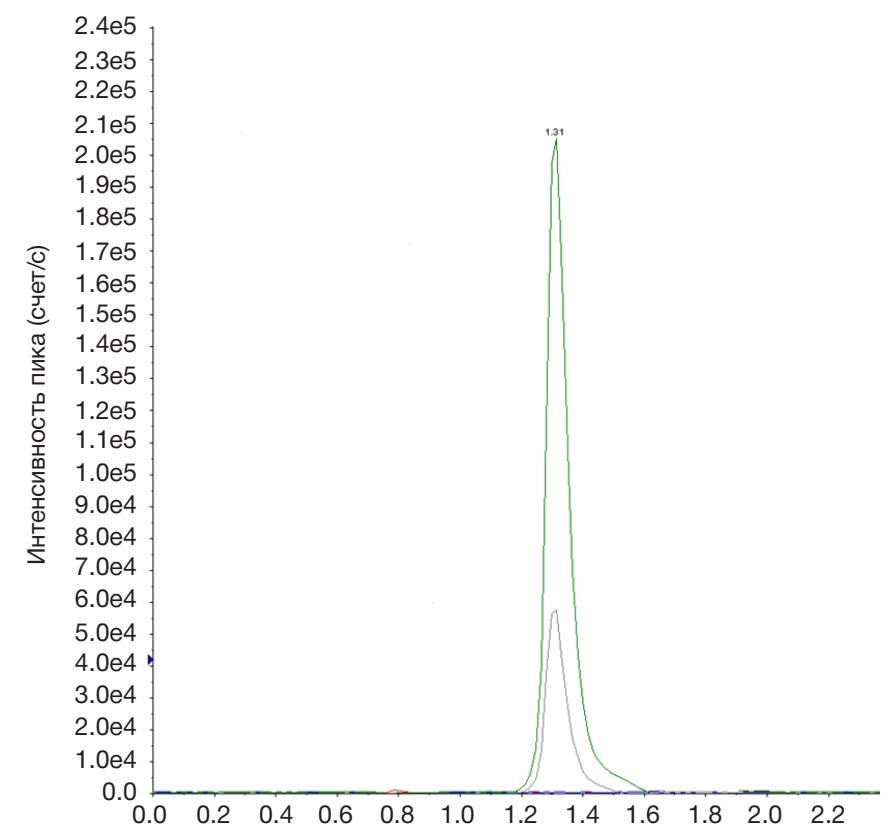

Рис. 4. Хроматограмма N-(5-этил-1,3,4-тиадиазол-2-ил)-2-пропилпентанамида деривата вальпроевой кислоты (внутрибрюшинно, мыши) в среднем в 1,8 раза больше, чем у вальпроевой кислоты [24]. Наличие противоэпилептического эффекта у синтезированного вальпроата подтверждено на моделях максимального электрошока и пентилентетразоловых судорог у мышей [25-26]. Учитывая, что наибольшую активность ВПЗ проявил в тесте с антагонистом ГАМКА-рецепторов пентилентетразолом, в настоящем исследовании оценивали его влияние на судороги, индуцированные другим антагонистом ГАМК - гидразидом изоникотиновой кислоты изониазидом. Проконвульсивный эффект изониазида связан с угнетением синтеза ГАМК за счет антагонизма с пиридоксальфосфатом, являющимся коферментом глутаматдекарбоксилазы, которая катализирует превращение глутамата в ГАМК. Судорожный синдром, нередко описываемый как эпилептический статус, представляет собой серьезное осложнение при лечении туберкулеза гидразидами изоникотиновой кислоты. Изониазид-индуцированные судороги плохо поддаются лечению обычными антиконвульсантами и не всегда могут быть предупреждены пиридоксином [27-28]. Известно, что вальпроаты могут дозозависимо угнетать развитие судорог, вызванных изониазидом 
Таблица. Влияние N-(5-этил-1,3,4-тиадиазол-2-ил)-2-пропилпентанамида (ВП3) на продолжительность латентного периода первого судорожного приступа и выживаемость мышей в тесте антагонизма с изониазидом (250 мг/кг, интраперитонеально)

\begin{tabular}{|c|c|c|c|c|}
\hline Серия опытов & Доза, мг/кг & $\begin{array}{c}\text { ЛП1, мин } \\
m \pm \text { SЕM }\end{array}$ & Число выживших/всего мышей & Выживаемость, \% \\
\hline ИР NaCІ + ИЗН & - & $31,25 \pm 2,03$ & $0 / 8$ & 0 \\
\hline ВПЗ + ИЗН & 75 & $47,75 \pm 2,42^{*}$ & $0 / 8$ & 0 \\
\hline ВПЗ + ИЗН & 150 & $72,13 \pm 4,28^{*}$ & $5 / 8$ & $62,5^{*}$ \\
\hline ВПЗ + ИЗН & 300 & $93,75 \pm 4,77^{*}$ & $7 / 8$ & $87,5^{*}$ \\
\hline ВПЗ + ИЗН & 450 & - & $8 / 8$ & $100^{*}$ \\
\hline
\end{tabular}

Примечание: * - различия с контролем (изониазид-индуцированные судороги у мышей, получавших ИР NaCl) статистически значимы ( $<$ 0,05; однофакторный дисперсионный анализ ANOVA c post-hoc тестом множественного сравнения Тьюки); \# - различия с контролем статистически значимь ( $<$ < 0,05; точный критерий Фишера). ВПЗ - вальпразоламид (N-(5-этил-1,3,4-тиадиазол-2-ил)-2-пропилпентанамид); ИЗН — изониазид; ИР 근 изотонический раствор натрия хлорида; ЛП1 - продолжительность латентного периода первого судорожного приступа.

[29]. В настоящем исследовании показано, что предварительное введение N-(5-этил-1,3,4-тиадиазол-2ил)-2-пропилпентанамида увеличивало латентный период судорог и уменьшало гибель мышей в тесте антагонизма с изониазидом. На основании этих сведений N-(5-этил1,3,4-тиадиазол-2-ил)-2-пропилпентанамид можно отнести к потенциальным противоэпилептическим средствам с улучшенным профилем безопасности.

\section{ВЫВОДЫ}

Результаты исследования подтверждают перспективность поиска новых антиконвульсантов путем модификации вальпроевой кислоты за счет введения в ее химическую структуру 1,3,4-тиадиазола. Преимущество синтезированного N-(5-этил-1,3,4-тиадиазол-2-ил)2-пропилпентанамида в способности предупреждать развитие изониазид-индуцированных судорог, недостаток нерастворимость в воде, что затрудняет получение инъекционных лекарственных форм. В дальнейшем для улучшения его биофармацевтических свойств предполагается получение нанокапсулированной формы с $\beta$-циклодекстрином. Методики идентификации $\mathrm{N}$-(5этил-1,3,4-тиадиазол-2-ил)-2-пропилпентанамида могут быть использованы для определения его подлинности и проведения фармакокинетических исследований.

\section{Литература}

1. Singh A, Trevick S. The epidemiology of global epilepsy. Neurol Clin. 2016 Nov; 34 (4): 837-47. PubMed PMID: 27719996.

2. Авакян Г. Н. Вопросы современной эпилептологии. Эпилепсия и пароксизмальные состояния. 2015; (4): 16-21.

3. Авакян Г. Н., Белоусова Е. Д., Бурд С. Г., Власов П. Н., Ермоленко Н. А., Киссин М. Я. и др. Проблемы эпилептологии Ключевые приоритеты, задачи, вызовы и способы их решения. Эпилепсия и пароксизмальные состояния. 2019; 11 (4): 395-406.

4. Kalilani L, Sun X, Pelgrims B, Noack-Rink V, Villanueva V. The epidemiology of drug-resistant epilepsy: A systematic review and meta-analysis. Epilepsia. 2018; 59 (12): 2179-93. PubMed PMID: 30426482

5. Авакян Г. Н., Власов П. Н., Жидкова И. А., Карлов В. А., Лебедева А. В., Михаловска- Карлова Е. П. и др. Заключение Совета экспертов по применению вальпроатов у пациенток с эпилепсией. Неврология, нейропсихиатрия, психосоматика. Эпилепсия. 2015; (1): 63-64.

6. Tomson T, Battino D, Perucca E. The remarkable story of valproic acid. Lancet Neurol. 2016 Feb; 15 (2): 141. PubMed PMID: 28463122.

7. Воронкова К. В., Никитин А. Э., Рудакова И. Г., Власов П. Н., Бурд С. Г., Лебедева А. В. и др. Современный выбор антиэпилептической терапии: этапы и рекомендации Эпилепсия и пароксизмальные состояния. 2018; 10 (2): 74-81.

8. Мухин К. Ю., Петрухин А. С., Миронов М. Б. Вальпроат натрия (Депакин) в достижении ремиссии у больных идиопатической генерализованной эпилепсией (долгосрочный катамнез). Неврологический журнал. 2004; (4): 34-39.

9. Perucca E. Pharmacological and therapeuti properties of valproate: a summary after 35 years of clinical experience. CNS Drugs. 2012; 16 (10): 695-714.

10. Бадалян О. Л., Бурд С. Г., Савенков А. А., Авакян Г. Г., Юцкова Е. В., Авакян Г. Н. Сравнительная оценка эффективности и безопасности производных вальпроевой кислоты: опыт применения. Эпилепсия и пароксизмальные

состояния. 2014; 6 (2): 39-44.

11. Шнайдер Н. А., Дмитренко Д. В. Хроническая интоксикация вальпроевой кислотой в эпилептологии: диагностика и лечение. Неврология, нейропсихиатрия, психосоматика. 2016; 8 (2): 94-99.

12. Sztajnkrycer MD. Valproic acid toxicity: overview and management. J Toxicol Clin Toxicol. 2002; 40 (6): 789-801. PubMed PMID:12475192.

13. Tomson T, Battino D, Perucca E. Valproic acid after five decades of use in epilepsy: time to reconsider the indications of a timehonoured drug. Lancet Neurol. 2016 Feb; 15 (2): 210-8. PubMed PMID: 26655849

14. Pessah N, Yagen B, Hen N, Shimshoni JA, Wlodarczyk B, Finnell RH, Bialer M. Design and pharmacological activity of glycinamide and $\mathrm{N}$-methoxy amide derivatives of analogs and constitutional isomers of valproic acid. Epilepsy Behav. 2011 Nov; 22 (3): 461-8. PubMed PMID:21959082.

15. Sun $X Y$, Wei CX, Deng XQ, Sun ZG, Quan ZS. Evaluation of the anticonvulsant activity of 6-(4-chlorophenyoxy)-tetrazolo[5,1-a] phthalazine in various experimental seizure models in mice. Pharmacological Reports: PR, 01 Mar 2010, 62 (2): 273-7. PubMed PMID: 20508282

16. Trojnar MK, Wierzchowska-Cioch E, Krzyzanowski M, Jargiełło M, Czuczwar SJ. New generation of valproic acid. Pol J Pharmacol. 2004 May-Jun; 56 (3): 283-8. PubMed PMID: 15215557.

17. Lin $Y L$, Bialer $M$, Cabrera RM, Finnell RH, Wlodarczyk BJ. Teratogenicity of valproic acid and its constitutional isomer, amide derivative valnoctamide in mice. Birth Defects Res. 2019 Aug 15; 111 (14): 1013-23. PubMed PMID: 30325584.

18. Haines KM, Matson LM, Dunn EN1, Ardinger CE, Lee-Stubbs R, Bibi D, McDonough $\mathrm{JH}$, Bialer M Comparative efficacy of valnoctamide and sec-butylpropylacetamide (SPD) in terminating nerve agent-induced seizures in pediatric rats. Epilepsia. 2019 Feb; 60 (2): 315-21. PMID: 30615805

19. Kaufmann D, Bialer M, Shimshoni JA, Devor M, Yagen B. Synthesis and evaluation of antiallodynic and anticonvulsant activity of 
novel amide and urea derivatives of valproic acid analogues. $J$ Med Chem. 2009 Nov 26; 52 (22): 7236-48. PubMed PMID 19877649.

20. Samur DN, Arslan R, Aydın S, Bektas N. Valnoctamide: The effect on relieving of neuropathic pain and possible mechanisms. Eur J Pharmacol. 2018 May 15; (827): 208-14. PubMed PMID: 29522726

21. Praena B, Bello-Morales R, de Castro F, López-Guerrero JA Amidic derivatives of valproic acid, valpromide and valnoctamide, inhibit HSV-1 infection in oligodendrocytes. Antiviral Res. 2019 Aug; (168): 91-99. PubMed PMID: 31132386.

22. Ornaghi S, Hsieh LS, Bordey A, Vergani P, Paidas MJ, van den Pol AN. Valnoctamide Inhibits Cytomegalovirus Infection in Developing Brain and Attenuates Neurobehavioral Dysfunctions and Brain Abnormalities. J Neurosci. 2017 Jul 19; 37 (29): 6877-93. PubMed PMID: 28630251

23. Jain AK, Sharma S, Vaidya A, Ravichandran V, Agrawal RK. 1,3,4-Thiadiazole and its Derivatives: A Review on Recent Progress in Biological Activities. Chem Biol Drug Des. 2013; (81): 557-76. PubMed PMID: 23452185

24. Малыгин А. С. Оценка острой токсичности и нейротоксичности нового амидного производного вальпроевой кислоты и 1,3,4-тиадиазола. Медицина. 2019; (3): 37-46.

\section{References}

1. Singh A, Trevick S. The epidemiology of global epilepsy. Neurol Clin. 2016 Nov; 34 (4): 837-47. PubMed PMID: 27719996.

2. Avakyan GN. Questions modern epileptology. Epilepsy and paroxysmal conditions. 2015; 7 (4): 16-21. Russian.

3. Avakyan GN, Belousova ED, Burd SG, Vlasov PN, Ermolenko NA Kissin MY, et al. Current trends in epileptology: priorities, challenges, tasks and solutions. Epilepsy and paroxysmal conditions. 2019; 11 (4): 395-406. Russian.

4. Kalilani L, Sun X, Pelgrims B, Noack-Rink V, Villanueva V. The epidemiology of drug-resistant epilepsy: A systematic review and meta-analysis. Epilepsia. 2018; 59 (12): 2179-93. PubMed PMID: 30426482.

5. Avakyan GN, Vlasov PN, Zhidkova IA, Karlov VA, Lebedeva AV, Mikhalovska-Karlova EP, et al. Conclusion of the Counci of Experts on the use of valproate in patients with epilepsy. Neurology, neuropsychiatry, psychosomatics. Epilepsy and paroxysmal conditions. 2015; 7 (1): 69. Russian.

6. Tomson T, Battino D, Perucca E. The remarkable story of valproic acid. Lancet Neurol. 2016 Feb; 15 (2): 141. PubMed PMID: 28463122.

7. Voronkova KV, Nikitin AE, Rudakova IG, Vlasov PN, Burd SG, Lebedeva AV, et al. Today's choice of antiepileptic therapy: stages and recommendations. Epilepsy and paroxysmal conditions. 2018; 10 (2): 74-81. Russian.

8. Mukhin KYu, Petrukhin AS, Mironov MB. Sodium valproate (Depakine) in achieving remission in patients with idiopathic generalized epilepsy (long-term follow-up). Neurological journal. 2004; (4): 34-39. Russian.

9. Perucca E. Pharmacological and therapeutic properties of valproate: a summary after 35 years of clinical experience. CNS Drugs. 2012; 16 (10): 695-714.

10. Badalyan OL, Burd SG, Savenkov AA, Avakyan GG, Yutskova EV, Avakyan GN. Comparative evaluation of the efficacy and safety of valproic acid derivatives. Epilepsy and paroxysmal conditions. 2014; 6 (2): 39-44. Russian.

11. Schneider NA, Dmitrenko DV. Chronic intoxication with valproic acid in epileptology: diagnosis and treatment. Neurology, neuropsychiatry, psychosomatics. 2016; 8 (2): 94-99. Russian.

12. Sztajnkrycer MD. Valproic acid toxicity: overview and management. J Toxicol Clin Toxicol. 2002; 40 (6): 789-801. PubMed PMID:12475192.

13. Tomson T, Battino D, Perucca E. Valproic acid after five decades of use in epilepsy: time to reconsider the indications of a timehonoured drug. Lancet Neurol. 2016 Feb; 15 (2): 210-8. PubMed PMID: 26655849
25. Малыгин А. С. Исследование противоэпилептической активности нового амидного производного вальпроевой кислоты и 1,3,4-тиадиазола. Эпилепсия и пароксизмальные состояния. 2019; 11 (4): 357-63.

26. Скачилова С. Я., Малыгин А. С., Попов Н. С., Демидова М. А., авторы; Владелец патента: «Всесоюзный научный центр по безопасности биологически активных веществ». N-(5-этил1,3,4-тиадиазол-2-ил)-2-пропилпентанамид, обладающий противоэпилептической и обезболивающей активностями. Патент РФ № 2672 887. 13.03. 2018.

27. Asehinde S, Ajayi A, Bakre A, Omorogbe O, Adebesin A, Umukoro S. Effects of Jobelyn ${ }^{\circledast}$ on Isoniazid-Induced Seizures, Biomarkers of Oxidative Stress and Glutamate Decarboxylase Activity in Mice Basic Clin Neurosci. 2018 Nov-Dec; 9 (6): 389-96. PMID: 30719253.

28. Minns AB, Ghafouri N, Clark RF. Isoniazid-induced status epilepticus in a pediatric patient after inadequate pyridoxine therapy. Pediatr Emerg Care. 2010 May; 26 (5): 380-1. PubMed PMID: 20453796

29. Bernasconi R, Klein M, Martin P, Portet C, Maître L, Jones RS et al. The specific protective effect of diazepam and valproate against isoniazid-induced seizures is not correlated with increased GABA levels. J Neural Transm.1985; 63 (2): 169-89. PubMed PMID: 3930661.

14. Pessah N, Yagen B, Hen N, Shimshoni JA, Wlodarczyk B, Finnell RH, Bialer M. Design and pharmacological activity of glycinamide and $\mathrm{N}$-methoxy amide derivatives of analogs and constitutional isomers of valproic acid. Epilepsy Behav. 2011 Nov; 22 (3): 4618. PubMed PMID:21959082.

15. Sun $X Y$, Wei CX, Deng $X Q$, Sun ZG, Quan ZS. Evaluation of the anticonvulsant activity of 6-(4-chlorophenyoxy)-tetrazolo[5,1-a] phthalazine in various experimental seizure models in mice. Pharmacological Reports: PR, 01 Mar 2010, 62 (2): 273-7. PubMed PMID: 20508282.

16. Trojnar MK, Wierzchowska-Cioch E, Krzyzanowski M, Jargiełło M, Czuczwar SJ. New generation of valproic acid. Pol J Pharmacol. 2004 May-Jun; 56 (3): 283-8. PubMed PMID: 15215557.

17. Lin $\mathrm{YL}$, Bialer $\mathrm{M}$, Cabrera RM, Finnell RH, Wlodarczyk BJ. Teratogenicity of valproic acid and its constitutional isomer, amide derivative valnoctamide in mice. Birth Defects Res. 2019 Aug 15; 111 (14):1013-23. PubMed PMID: 30325584.

18. Haines KM, Matson LM, Dunn EN1, Ardinger CE, Lee-Stubbs R, Bibi D, McDonough JH, Bialer M. Comparative efficacy of valnoctamide and sec-butylpropylacetamide (SPD) in terminating nerve agentinduced seizures in pediatric rats. Epilepsia. 2019 Feb; 60 (2): 315-21. PMID: 30615805

19. Kaufmann D, Bialer M, Shimshoni JA, Devor M, Yagen B. Synthesis and evaluation of antiallodynic and anticonvulsant activity of novel amide and urea derivatives of valproic acid analogues. J Med Chem. 2009 Nov 26; 52 (22): 7236-48. PubMed PMID 19877649.

20. Samur DN, Arslan R, Aydın S, Bektas N. Valnoctamide: The effect on relieving of neuropathic pain and possible mechanisms. Eur J Pharmacol. 2018 May 15; (827): 208-14. PubMed PMID: 29522726.

21. Praena B, Bello-Morales R, de Castro F, López-Guerrero JA. Amidic derivatives of valproic acid, valpromide and valnoctamide, inhibit HSV-1 infection in oligodendrocytes. Antiviral Res. 2019 Aug; (168): 91-99. PubMed PMID: 31132386.

22. Ornaghi S, Hsieh LS, Bordey A, Vergani P, Paidas MJ, van den Pol AN. Valnoctamide Inhibits Cytomegalovirus Infection in Developing Brain and Attenuates Neurobehavioral Dysfunctions and Brain Abnormalities. J Neurosci. 2017 Jul 19; 37 (29): $6877-$ 93. PubMed PMID: 28630251

23. Jain AK, Sharma S, Vaidya A, Ravichandran V, Agrawal RK. 1,3,4-Thiadiazole and its Derivatives: A Review on Recent Progress in Biological Activities. Chem Biol Drug Des. 2013; (81): 557-76. PubMed PMID: 23452185.

24. Malygin AS. Assessment of acute toxicity and neurotoxicity of a 
new amide derivative of valproic acid and 1,3,4-thiadiazole. The medicine. 2019 (3): 37-46. Russian.

25. Malygin AS. Study on the antiepyleptic activity of the new amide derivative of valproic acid and 1,3,4-thiadiazole. Epilepsy and paroxysmal conditions. 2019; 11 (4): 357-63. Russian.

26. Skachilova SYa, Malygin AS, Popov NS, Demidova MA, avtory; Vladelets patenta: «Vsesoyuznyy nauchnyy tsentr po bezopasnosti biologicheski aktivnykh veshchestv». N-(5-etil-1,3,4-tiadiazol-2il)-2-propilpentanamid, obladayushchiy protivoepilepticheskoy i obezbolivayushchey aktivnostyami. Patent RU № 2672887. 13.03. 2018. Russian.

27. Bernasconi R, Klein M, Martin P, Portet C, Maître L, Jones RS, et al. The specific protective effect of diazepam and valproate against isoniazid-induced seizures is not correlated with increased GABA levels. J Neural Transm.1985; 63 (2): 169-89. PubMed PMID: 3930661.

28. Asehinde S, Ajayi A, Bakre A, Omorogbe O, Adebesin A, Umukoro S. Effects of Jobelyn ${ }^{\oplus}$ on Isoniazid-Induced Seizures, Biomarkers of Oxidative Stress and Glutamate Decarboxylase Activity in Mice Basic Clin Neurosci. 2018 Nov-Dec; 9 (6): 389-96. PMID: 30719253.

29. Minns AB, Ghafouri N, Clark RF. Isoniazid-induced status epilepticus in a pediatric patient after inadequate pyridoxine therapy. Pediatr Emerg Care. 2010 May; 26 (5): 380-1. PubMed PMID: 20453796. 